\title{
Factor de impacto, una herramienta imperfecta pero imprescindible
}

\section{Impact factor, an imperfect but essential tool}

\author{
E. Fernandez-Mondéjar ${ }^{\mathrm{a}}$,* , D. Hugo Ceraso ${ }^{\mathrm{b}}$, F. Gordo Vidal ${ }^{\mathrm{c}}$, \\ F. Guerrero López ${ }^{\mathrm{a}}$ y M. Colmenero Ruiz ${ }^{\mathrm{a}}$
}

\author{
a Unidad de Cuidados Intensivos, Hospital Universitario Virgen de las Nieves, Granada, España \\ bUnidad de Terapia Intensiva, Hospital Juan Ferández, Buenos Aires, Argentina \\ 'Servicio de Medicina Intensiva, Hospital de Henares, Coslada, Madrid, España
}

Recibido el 3 de septiembre de 2010; aceptado el 3 de septiembre de 2010

Disponible en Internet el 28 de septiembre de 2010

La obtención de «factor de impacto» (FI) por la revista Medicina Intensiva, supone un paso importante en el proceso de crecimiento y de reconocimiento de la misma y a través de ella, de expansión de nuestra especialidad.

Cuando a mediados de 2006 se produjo el relevo en la dirección de Medicina Intensiva, todo el equipo editorial nos propusimos varios objetivos; uno de ellos fue considerado un objetivo estratégico, y consistía en la inclusión de nuestra revista en el Science Citation Index $(\mathrm{SCl})$ y Journal Citation Report (JCR) y obtener $\mathrm{FI}^{1}$. Previamente, con el anterior equipo editorial dirigido por el Dr. Miguel Ángel de la Cal, se habían dado dos pasos trascendentales para la internacionalización de nuestra revista: por una parte fue aceptada como órgano oficial de la Federación Panamericana e Ibérica de Sociedades de Medicina Crítica y Terapia Intensiva $(\mathrm{FEPIMCTI})^{2}$ y por otra, se incluyó nuestra revista en el Index Medicus-Medline. Estos logros se han visto ahora culminados con la consecución del objetivo estratégico antes mencionado; la inclusión de Medicina Intensiva en el $\mathrm{SCl}$ y JCR es un hecho y por tanto la obtención de factor de impacto.

Dada la creciente necesidad de evaluación tanto de la actividad científica como de sus resultados, la cuantificación de los mismos mediante índices como el $\mathrm{FI}$ es en la actualidad una exigencia para cualquier publicación científica. Parte del prestigio de una publicación se mide en función de su FI, pero no solo se trata de cuantificar aspectos intangibles como el reconocimiento o el prestigio sino también de otros mucho más materiales. Un caso paradigmático de esta necesidad lo constituye su empleo como herramienta para obtener la financiación de proyectos científicos. Esta se encuentra inmersa en un proceso muy competitivo que requiere datos objetivos capaces de cuantificar y comparar la actividad y los resultados del acto científico. Se pretende por tanto eliminar al máximo la subjetividad que en definitiva implicaría arbitrariedad e injusticia y basar la decisión de financiación en criterios más objetivos y reconocidos por todos. Por supuesto que además del $\mathrm{Fl}$ existen otros índices bibliométricos, algunos sin duda más precisos, pero el FI sigue siendo fundamental.

Somos conscientes de las muchas limitaciones del FI, quizás la más importante es que solo da idea del empleo científico de una revista y no necesariamente de su utilidad en la práctica clínica. Asimismo, hemos de reconocer que se trata de un índice relativamente simple y potencialmente manipulable. Sin embargo, aunque estas y otras críticas

*Autor para correspondencia.

Correo electrónico: enrique.fernandez.mondejar.sspa@juntadeandalucia.es (E. Fernandez-Mondéjar). 
pueden ser ciertas, no creemos que ahora sea el momento de entrar en estas consideraciones sino de alegrarnos por pasar a formar parte del selecto grupo de publicaciones que han conseguido este reconocimiento. Concretamente en el ámbito de la Medicina Intensiva o crítica «critical care medicine» son otras veintiuna revistas, siendo la nuestra la primera en español. Si la búsqueda se realiza entre las editadas en España «Spain» el círculo de las elegidas comprende a veinticinco.

\section{El futuro próximo}

La consecución de un objetivo estratégico como el FI no puede considerarse un fin en sí mismo sino que ha de plantearse como medio para conseguir un objetivo más general. En nuestro caso, este no es otro que lograr que los mejores investigadores de habla hispana consideren a Medicina Intensiva un medio válido para dar a conocer algunas de sus investigaciones.

Muchos tenemos la sensación de que en los más de 30 años de nuestra especialidad, el nivel científico de los intensivistas hispanoparlantes ha crecido más que el de la revista. Esta sensación también existe en otras especialidades y las causas pueden ser múltiples pero con un común denominador: el idioma. La globalización del conocimiento, la necesidad de competir internacionalmente para obtener el reconocimiento y prestigio más allá de nuestras fronteras, ha situado de forma indiscutible al inglés como idioma científico frente a todos los demás incluyendo al español ${ }^{3}$. Algunos lo aceptan como un hecho consumado sin posibilidad de reacción aunque hay iniciativas dirigidas a fomentar las publicaciones médicas en español (MEDES) ${ }^{4}$ y es posible crear foros científicos potentes en nuestro idioma. Otras publicaciones han optado por un enfoque pragmático, y han decidido publicar en los dos idiomas o directamente en inglés, y los resultados a nivel bibliométrico parecen positivos aunque con un coste económico elevado que probablemente sería inaceptable si se contempla desde un punto de vista empresarial.

La polémica está abierta y en un futuro próximo habrá que tomar decisiones en este sentido.

Para finalizar creemos que hoy es el momento de congratularnos porque con el esfuerzo de todos, fundamentalmente de los autores con sus manuscritos y de los revisores con sus críticas y recomendaciones, hemos conseguido un objetivo importante.

Sabemos que la obtención de FI supone contar con una herramienta que aún siendo imperfecta, nadie dudará que es imprescindible para toda publicación científica. Ha sido un objetivo que ha tardado cuatro años en alcanzarse y que finalmente se ha conseguido. Ahora el aumentar progresivamente la calidad y el factor de impacto de la revista sigue siendo trabajo de todos.

\section{Bibliografía}

1. Fernández-Mondéjar E. Nueva dirección en Medicina Intensiva. ¿es realista pretender que nuestra revista refleje la actividad de los intensivistas de habla hispana? Med Intensiva. 2006;30:423-4.

2. Celis Rodríguez E, Cabré Pericás L, de la Cal López MA. Medicina Intensiva, Órgano oficial de la Federación Panamericana e lbérica de Sociedades de Medicina Crítica y Terapia Intensiva. Med Intensiva. 2004;28:297-8.

3. Fernandez Mondejar E. Medicina Intensiva en español. Med Intensiva. 2010;34:85-6.

4. [Consultado 1/9/2010]. Disponible en: http://www.lilly.es/Nitro/ foundation/templates/medes-search.jsp?page $=3010$. 